\title{
Future pharmaceutical research: the need to look beyond science
}

\author{
"Regardless of the innovation model chosen for future medicinal R\&D projects, \\ it is obvious that opening the process, for instance by including external resources \\ and knowledge, will become critical."
}

\begin{abstract}
Keywords $\bullet$ contract research organization $\bullet$ drug discovery $\bullet$ open innovation - pharmaceutical research $\bullet$ research management $\bullet$ venture capital $\bullet$ virtual company
\end{abstract}

Pharmaceutical and medicinal R\&D projects have evolved during recent decades into extremely intricate constructs. This complexity applies for drug discovery and for other fields such as medicinal technology or medical diagnostics. Big pharmaceutical companies recognized early on the need to collaborate with external organizations to fill their product pipeline and thus present a bright future to stakeholders. Other innovative medicinal businesses are also increasingly focusing on external collaborations although their doing so has attracted less public attention than the big pharmaceutical companies.

\section{Getting product development right}

Accelerated knowledge generation in medicinal, chemical and biological sciences - including the unraveling of molecular, biochemical and cellular networks, rational drug design, new materials, chemical biology and novel medicinal diagnostic tools - has several consequences for successful product development. First, even for big global companies, it is almost impossible to provide all relevant knowledge and technologies inhouse. Second, the management of productdevelopment projects is increasingly complex and requires skilled professionals with a strong background in both management and the natural sciences. However, grasping the scientific complexity of the project does not completely address the challenge of today's innovation processes: the total value chain must be considered, including marketing, regulatory matters, manufacturing and quality-control issues.
Because entirely in-house development projects are going to be less dominant in future research, project designs that incorporate external sources are drawing increasing attention [1,2]. A broad range of constructs has been described and successfully demonstrated. In contrast to the isolated confidential research project in an organization, incorporation a merger with, or an acquisition of, another organization - can successfully draw knowledge into an organization without disclosing internal knowledge. This pathway is a popular one in drug development (e.g., Roche's acquisition of Genentech and the merger of Sanofi and Aventis) as well as in the life sciences (e.g., the recent acquisition of Life Technologies by Thermo Fisher). In addition to a high initial cost, however, and in particular the investment itself, an enormous managerial capacity is required to integrate the organizations involved. Furthermore, the knowledge and the experts necessary for development projects often are globally distributed and not accessible by a single merger or acquisition. More innovative business strategies have therefore been developed in recent years.

Although mergers and acquisitions do not 'open' the innovation process because they basically draw knowledge into the firm, new strategies are generating pathways to access knowledge that is specific for the project and distributed globally over several organizations. This kind of flexible R\&D collaboration can range from an integrated (pharmaceutical) company concept to a 'virtual company'. An even more extreme construct is the widely discussed 'open innovation'.

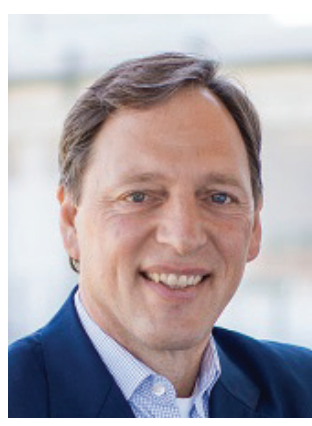

Stefan Seeger* *Department of Chemistry, Business Chemistry Group, Winterthurerstrasse 159, 8057 Zurich, Switzerland Tel.: +41446354451 Fax: +41446356813 sseeger@chem.uzh.ch 
The integrated company model retains all core functions in the primary company, but individual tasks that are not core competencies are outsourced to suppliers, for example, contract research organizations or contract manufacturing organizations. The integrated concept keeps the core functions and key knowledge in-house and usually covers the whole development and commercialization process, as in the case of a typical drug-discovery process with preclinical research, clinical Phases I-III, US FDA regulatory work, up-scaling, manufacturing and marketing.

\section{Virtual companies}

The recently emerged 'virtual company' concept, however, addresses the need for accessing knowledge from outside in a much more aggressive way: the core is a small organization coordinating the development process and usually holding the intellectual property (IP) rights [3]. This entity is the core of a consortium, that is, partners involved in the $\mathrm{R} \& \mathrm{D}$ process, such as contract research organizations, publicly funded research institutions, eventually new chemical entity providers and global (pharmaceutical) company investors, which it coordinates. Virtual company structures are applied mainly to a part of the drug-discovery process, in particular the preclinical phase and clinical Phases I and II. The goal is to achieve the proof-of-concept faster and at lower costs than an integrated pharmaceutical company can. The structure is favorable for using external knowledge and capacities: the virtual company, which is an organizationally and legally independent entity outside the dominating global player, is broadly free to choose appropriate partners; the main criteria should be availability of relevant know-how, expected speed, appropriate resources and costs. Although the virtual company concept has been applied in the past mainly to drug discovery, it can serve as an appropriate structure in other medicinal research fields as well.

The virtual company requires at least partially porous boundaries among the partners but is characterized to a large extent by a closed shell around the participating collaborators.

\section{Open innovation}

An even further 'opening' of the $R \& D$ process is called 'open innovation', a term introduced by Henry Chesbrough in 2003 [4]; Chesbrough et al. stated: "open Innovation is the use of purposive inflows and outflows of knowledge to accelerate internal innovation, and expand the markets for external use of innovation, respectively" [5]. An extreme form of open innovation is called 'crowd-sourcing' in which the task is communicated via the internet to a broad group of potential problem solvers (i.e., the crowd). Experts all over the world are asked to contribute. Useful ideas and solutions are identified and further developed [6]. Eli Lilly's InnoCentive platform is the first example of crowd-sourcing in the pharmaceutical industry.

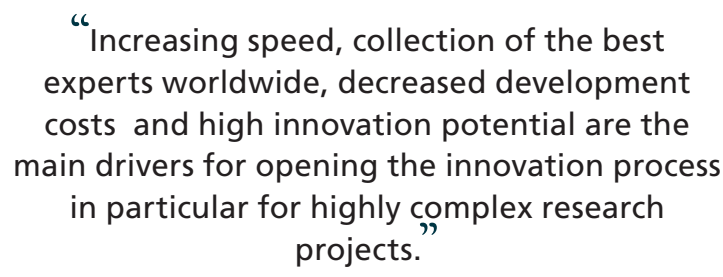

The industry's trend towards collaborative $\mathrm{R} \& \mathrm{D}$ and licensing already bears basic principles of open innovation [7]. The advantages of open innovation concepts for a pharmaceutical or medical company are the open in-flow of new ideas and solutions to the target problem. They also include business, spin-off or license options that may appear. In other words, aside from the expected information in-flow, open innovation and, in particular, crowd-sourcing have a reasonable potential to generate new and unexpected business opportunities.

Increasing speed, collection of the best experts worldwide, decreased development costs and high innovation potential are the main drivers for opening the innovation process in particular for highly complex research projects.

Whether companies in the pharmaceutical and medicinal business should be advised to open up the organization's boundaries for $\mathrm{R} \& \mathrm{D}$ projects, however, cannot be generalized. The project, internal available knowledge, complexity of the development process, management capabilities and, last but not least, the IP situation in the market are all factors. The increasing involvement of external resources - from a complete inhouse project to an integrated company concept to a virtual company construct to open innovation up to the extreme form of crowd-sourcing - corresponds with an increasing disclosure of internal knowledge. This issue is important and leads companies to hesitate in opening up the innovation process. In addition, patenting of results and ownership issues become more complicated if several organizations are involved. Here, prior to the start of the project, lengthy negotiations can be necessary, which absorb time and management capacity and still do not exclude litigation at a later date.

One major critical success factor for all ideas is an excellent management team for preparation, coordinating and finalizing the project. Inappropriate preparation, unclear IP issues, wrong partner selection, low motivation of individual team members, among other factors, are potential reasons for failure of the complete project. 


\section{Future perspective}

Regardless of the innovation model chosen for future medicinal R\&D projects, it is obvious that opening the process, for instance by including external resources and knowledge, will become critical. As a consequence, organizations must be transparent concerning their goals and what they expect to receive, and they must accept a lower level of confidentiality. Furthermore, the leading organization has to provide an experienced management team. Selecting the best suppliers and partners, adjusting each against the others and keeping them motivated requires such an experienced team. Beyond this, each of the member units, which may be distributed over different continents, must be aware of the final goal and the current status; all participants need to be kept motivated during their respective periods of involvement. Members should experience a full appreciation of their individual contributions. Therefore, the leading management team should ensure high transparency concerning

\section{References}

1 Munos B. Lessons from 60 years of pharmaceutical innovation. Nat. Rev. Drug Discov. 8(12), 959-968 (2009).

2 Schumacher A, Germann PG, Trill H, Gassmann O. Models for innovation in the pharmaceutical industry. Drug Discov. Today 18(23-24), 1133-1137 (2013).

3 Forster SP, Stegmaier J, Spycher R, Seeger S. Virtual pharmaceutical companies: collaborating flexibly in pharmaceutical development. Drug Discov. Today 19(3), 348-355 (2013). the organizational, scientific and commercial aspects of the project. However, these duties of the leading team are only one side of the coin: the members of the consortium must also be able to grasp the business issues and interdependencies. In other words, the scientists, researchers and engineers also have to be interested in an integrated perspective on the project; consequently, there is a strong need to look beyond the science.

\section{Financial \& competing interests disclosure}

The author has no relevant affiliations or financial involvement with any organization or entity with a financial interest in or financial conflict with the subject matter or materials discussed in the manuscript. This includes employment, consultancies, honoraria, stock ownership or options, expert testimony, grants or patents received or pending, or royalties.

No writing assistance was utilized in the production of this manuscript.

4 Chesbrough HW. The era of open innovation. Sloan Manag. Rev. 44(3), 35-41 (2003).

5 Chesbrough H, Vanhaverbeke W, West J. Open innovation: Researching a New Paradigm. Oxford University Press, Oxford, UK (2006).

6 Lessl M, Bryans JS, Richards D, Asadullah K. Crowd sourcing in drug discovery. Nat. Rev. Drug Discov. 10, 241-242 (2011).

7 Hughes B, Warham J. Knowledge arbitrage in global pharma: a synthetic view of absorptive capacity and open innovation. R\&D Manag. 40(3), 324-343 (2010). 